\title{
Ethanol from sugar beet in The Netherlands: energy production and efficiency
}

\author{
Hans Langeveld ${ }^{a}$, Gerrie van de Ven ${ }^{b}$, Sander de Vries ${ }^{b}$, L. van den Brink ${ }^{c}$, C. de Visser \\ ${ }^{a}$ University of Wageningen, Plant Research International, Wageningen, The Netherlands; ${ }^{b}$ University \\ of Wageningen, Department of Plant Sciences, Wageningen, The Netherlands; ${ }^{c}$ University of \\ Wageningen, Applied Plant Research, Lelystad, The Netherland - hans.langeveld@wur.nl
}

\begin{abstract}
Prospects for ethanol production from sugar beet in The Netherlands have been analysed using measured production data from two experimental farms and literature on beet to ethanol conversion. The analysis includes four phases of ethanol production including beet cultivation and harvesting, transport to the factory, conversion into ethanol and distribution of the ethanol to distribution points. Assumptions have been explained and discussed. Under the prevailing conditions, ethanol production from sugar beet shows to be reasonably energy efficient. Starting from crop yields of 70 and 72 ton/ha for Westmaas (located on a clay soil) and Valthermond (former peat soil area), ethanol yield amounts to 5.6 and 5.8 ton/ha, respectively. At a gross energy production of 152 and 154 GJ ha ${ }^{-1}$ and an energy use of 120 and $117 \mathrm{GJ} / \mathrm{ha}$, a net energy production has been calculated of 32 (Westmaas) and 37 (Valthermond) GJ/ha. Crop and ethanol yields are above those reported elsewhere, as is energy use per hectare which is related to crop yield. Energy use per ton of ethanol is comparable to literature. Energy efficiency (1.3) is similar to that reported by Mortimer et al. (2004), but higher figures for sugar beet have been reported (GTZIFNR, 2006). Differences are explained by differences in artificial fertilizer, crop protection agent and diesel application rates, distances for transportation and energy use during conversion. Applying alternative energy generating technology at the ethanol factory as depicted by Mortimer et al. (2004) suggests that considerable energy gains can be realised. Another source of variation is the allocation ratio of energy to ethanol and by-products. The calculations presented in this paper suggest that the prospects for ethanol production from sugar beet in Europe can be considerable, if energy inputs can be reduced, by using crop residues to produce (part of) the energy required during conversion and by improving conversion efficiency.
\end{abstract}

Keywords: sugar beet, ethanol, bioenergy, energy efficiency

\section{Introduction}

While the demand for biofuel feedstocks is growing rapidly, it is debated whether the feedstock can be produced sustainably. Biofuel feedstock production should further be economically viable and socially acceptable. This requires a thorough analysis of possible biomass availability, energy efficiency and greenhouse gas (GHG) emission reduction. Many EU countries have embraced biomass and especially bioenergy crops as an important source of renewable energy. It remains unclear, however, which energy crops will play a role and how and where the required biomass can be grown. Sugar beet could play an important role as provider of ethanol feedstock, provided it generates sufficient net energy and can be produced in a sustainable way. In this study, we calculate the amount of net energy that can be produced and energy efficiency of the production chain, based on measured crop yields and inputs at two experimental farms in The Netherlands. Results will be compared to literature.

\section{Methods and materials}

\section{System boundaries}

In our study, we will refer to ethanol production from sugar beet as a process existing of four subprocesses:

- Phase I: direct and indirect energy use related to crop production and use of inputs, including seed, fertilizer, chemicals and machinery; 
- Phase II: direct and indirect energy use related to transport of (soiled) crop to the factory;

- Phase III: direct and indirect energy use for cleaning of sugar beet, conversion into ethanol, upgrading of ethanol and (if applicable) storage and cooling;

- Phase IV: direct and indirect energy use related to distribution of ethanol to users.

This approach guarantees the inclusion of total energy use in the production chain. In some studies, no reference is made to transportation or distribution. Our analyses do not include ethanol combustion in engines, but end with ethanol distribution to the consumer. As to data sources, we are using measured parameter values for crop production at the farm scale and standard parameter values for other data required.

\section{Phase I: Crop cultivation}

We have selected two typical sugar beet production regions in The Netherlands with different soil types and rotations. Production data refer to two experimental farms, Westmaas and Valthermond to allow a detailed analysis of all activities, inputs and yields. The Westmaas farm is located in the old marine clay area in the South-west of the country, representing production conditions on heavy clay soils. Generally, the rotation includes potato, cereals, and onions in addition to sugar beet (a 1:4 rotation). Organic matter content in Westmaas is $2.2 \%$. Valthermond is located in the North-east, in the area of former peat soils of the 'Veenkoloniën'. Soils are high to very high in organic matter (usually around $10 \%$ ), well drained and relatively light. The rotation in this area includes starch and seed potato (sometimes half of the farm area), cereals, and sugar beet. In Valthermond sugar beet are cultivated in a 1:6 rotation.

Indirect energy use for manufacturing agro-chemicals and their applications have been calculated from the amounts applied in 2005, 2006 and 2007 and energy values from literature (Bos et al., 2007). For some crop protection agents, energy values were missing; these values have been estimated. Indirect energy use due to mechanisation is based on Bos et al. (2007). Mechanisation on both farms is similar and variation between years has been neglected, resulting in one average value. Beet yield and soil contamination, i.e. soil attached to the beets that needs to be washed off in the factory, were measured.

\section{Phase II and IV:Transport and distribution}

Beet (and soil) transportation distance from field to factory and ethanol transportation distance to the distribution points have been estimated, as currently no ethanol production from sugar beet exists. We have assumed $100 \mathrm{~km}$ for both pre- and post-processing phase for both farms, a reasonable value given the size of The Netherlands. Energy use for transportation is 1,1053 MJ per (ton*km) (see Annex for details). The transportation distance from field to factory is slightly higher than the $80 \mathrm{~km}$ used by Mortimer et al. (2004). Distribution distance (roundtrip) from factory to distribution point in the UK according to the same source is much higher larger (450 versus $100 \mathrm{~km}$ ).

\section{Phase III: Conversion to ethanol}

Energy use related to shedding, diffusion, pasteurisation, fermentation, and distillation as well as input use and production of by-products is based on Mortimer et al. (2004). For each step, energy inputs were defined assuming one single steam or electricity generation efficiency. We have chosen one of three alternative models presented in this study, where energy for sugar to ethanol conversion is derived from a natural-gas fired boiler with additional electricity from the grid. Possible differences between the UK and The Netherlands are not considered. For the conversion efficiency, expressed as ton ethanol per ton of sugar beet we have used the value reported by the Dept. of Transport (2007) of 0.080 , which is slightly higher than the value of 0.078 used by Mortimer et al. (2004). Data for beet to ethanol conversion, i.e. steps in processing, their efficiency and input use (not discussed here in detail), have been taken from Mortimer et al. (2004), as was the value for energy contents of ethanol $\left(26.7 \mathrm{GJ} \mathrm{t}^{-1}\right)$. 


\section{Energy allocation}

An important parameter is the share of the energy requirement during production, transportation and conversion of sugar beet that is allocated to the main product (ethanol). As the by-product of the process can be used as animal feed, it is considered a useful product with economic and energetic value. By-products (mainly pulp) can replace part of the components in animal feed that would otherwise originate from other crops. As cultivation, transportation and refinement of animal feed would consume energy as well, the energy used during the production of the pulp is usually subtracted from the gross energy use for ethanol production.

Basically, there are several ways to divide the energy input between the main and the by-product. One way is according to the energy content of each of them. One alternative is to follow the economic value of main and by-product, which has the disadvantages of fluctuating with price changes. Following Mortimer et al. (2004), we attributed an average of $77.5 \%$ of energy inputs to ethanol $(64 \%$ of energy applied during crop cultivation, $67 \%$ during crop transport, $79 \%$ during conversion and $100 \%$ during ethanol distribution) according to the economic value. Although allocation rates applied by EISayed et al. (2003) and Dept. of Transport (2007) are lower (67 and 60\%, respectively). It was decided to stick to Mortimer et al. because most of our assumptions follow this study and also to prevent too optimistic assessments for energy use.

\section{Results}

\section{Sugar beet production}

Input use for sugar beet cultivation and yields for the years 2005-2007 as well as three-year averages for Westmaas and Valthermond are presented in Table 1. In Westmaas nutrient application to sugar beet is by artificial fertilizers only, as manure in the clay areas of the South-west generally is applied elsewhere in the rotation. Average fertilizer application rates are $145 \mathrm{~kg}$ of nitrogen, $48 \mathrm{~kg}$ of phosphate and $80 \mathrm{~kg}$ of potassium oxide per ha. In Valthermond the phosphate requirements of the crop are supplied by manure, leading also to a much lower application rate of nitrogen and a slightly lower application rate of potassium.

Table 1. Characteristics of sugar beet production in Westmaas and Valthermond ${ }^{1}$

\begin{tabular}{|c|c|c|c|c|c|c|c|c|c|}
\hline & \multirow[t]{2}{*}{ Unit } & \multicolumn{4}{|c|}{ Westmaas } & \multicolumn{4}{|c|}{ Valthermond } \\
\hline & & 2005 & 2006 & 2007 & Avg. & 2005 & 2006 & 2007 & Avg. \\
\hline$N$ fertilizer & $\mathrm{kg} \mathrm{N} \mathrm{ha}^{-1}$ & 140 & 150 & 145 & 145 & 56 & 28 & 28 & 37 \\
\hline$P$ fertilizer & $\mathrm{kg}^{-1} \mathrm{P}_{2} \mathrm{O}_{5}$ & 76 & 0 & 70 & 48 & 0 & 0 & 0 & 0 \\
\hline$K$ fertilizer & $\mathrm{kg} \mathrm{K}_{2} \mathrm{O} \mathrm{ha}^{-}$ & 0 & 120 & 120 & 80 & 75 & 75 & 60 & 70 \\
\hline Manure & $\mathrm{T} \mathrm{ha}^{-1}$ & 0 & 0 & 0 & 0 & 25 & 6 & 25 & 19 \\
\hline$C P A^{1}$ & $\mathrm{~kg}$ a.i. $\mathrm{ha}^{-1}$ & 3.8 & 4.1 & 4.6 & 4.2 & 4.5 & 4.2 & 4.0 & 4.2 \\
\hline Diesel & $\mathrm{kg} \mathrm{ha}^{-1}$ & 133 & 151 & 207 & 164 & 128 & 122 & 122 & 124 \\
\hline Yield $^{2}$ & $\mathrm{tha}^{-1}$ & 84.0 & 70.2 & 55.1 & 69.8 & 74.2 & 71.1 & 71.4 & 72.2 \\
\hline Sugar $^{2}$ & $\mathrm{tha}^{-1}$ & 14.3 & 11.6 & 10.2 & 12.0 & 12.7 & 12.0 & 12.9 & 12.5 \\
\hline Tare & $\%$ & 15.9 & 13.1 & 15.4 & 14.8 & 14.0 & 13.2 & 10.1 & 12.4 \\
\hline
\end{tabular}

${ }^{1} \mathrm{CPA}=$ crop protection agent; a.i. $=$ active ingredient. ${ }^{2}$ Including $5 \%$ beet tops.

Average application of crop protection agents, mainly herbicides is $4.2 \mathrm{~kg}$ of active ingredient per hectare for both locations. Diesel use during crop production is on average $164 \mathrm{~kg} \mathrm{ha}^{-1}$ for Westmaas against $128 \mathrm{~kg} \mathrm{ha}^{-1}$ for Valthermond, mainly due to the heavy soils on the latter farm. Beet yield shows considerable variation between years, especially in Westmaas, but average values over the three years for Westmaas and Valthermond are comparable. The amount of soil that is entering the harvest process is relatively high, especially for the clay soils of Westmaas. 


\section{Energy use}

Total energy use during cultivation is 15-19 GJ/ha in Westmaas and 10-11 GJ/ha on Valthermond (Figure 1). Most energy is used for farming activities requiring diesel, followed by (in)direct energy use for production of artificial fertilizers and of crop protection agents. Energy required for manure (e.g. transport, indirect energy use) is not included. Total energy use in Westmaas exceeds that in Valthermond mainly because of differences in artificial fertilizer application rates. Diesel consumption in Westmaas further show considerable variation mainly because of extra activities required in 2006 and 2007. Variations in Valthermond in this respect are much smaller. Please note that this figure relates to total energy use, thus allocated to ethanol as well as to the by-product.



Figure 1. Energy use during cultivation ${ }^{1}$

${ }^{1}$ All energy, thus referring to ethanol and by-products. Wm refers to Westmaas; Vm to Valthermond; diesel use includes all cultivation activities requiring diesel; nutrients includes artificial fertilization only plus seed use; CPAs = Crop Protection Agents.

Allocated energy use during beet and ethanol production, transportation and distribution is presented in Table 2. Allocated energy requirements for cultivation vary between 6 and $12 \mathrm{GJ} \mathrm{ha}^{-1}$ with the highest values on the clay soils of Westmaas. The average energy use for cultivation sugar in Westmaas is about $60 \%$ higher than for cultivation in Valthermond. Energy inputs for cultivation make up $9 \%$ of the total energy use in Westmaas and $6 \%$ in Valthermond. The energy requirements for transportation are similar $\left(6.1 \mathrm{GJ} \mathrm{ha}^{-1}\right)$ for both locations, as average yields and transportation distances are similar. Energy use during conversion is just over $100 \mathrm{GJ} \mathrm{ha}^{-1}$, and absorbs 85 to $89 \%$ of the total energy input. Ethanol distribution requires very little energy, generally less than $1 \%$ of the total. Total energy inputs per ha amount to $120 \mathrm{GJ}$ in Westmaas and $117 \mathrm{GJ}$ in Valthermond.

Table 2. Energy use during four steps towards the production of ethanol from sugar beet in GJ ha ${ }^{-1}$. Between brackets the share of each production phase in the total energy use is given in percentages.

\begin{tabular}{|l|l|c|c|c|c|c|}
\hline Location & Year & \multicolumn{5}{|c|}{ Energy use } \\
\hline & & Cultivation & Transportation & Conversion & Distribution & Total \\
\hline Westmaas & 2005 & 9.5 & 7.3 & 120.9 & 0.7 & 138.5 \\
\hline & 2006 & 10.6 & 6.2 & 105.6 & 0.7 & 123.1 \\
\hline & 2007 & 12.3 & 4.8 & 79.8 & 0.5 & 97.4 \\
\hline & Avg. & $\mathbf{1 0 . 8 ( 9 \% )}$ & $\mathbf{6 . 1 ( 5 \% )}$ & $\mathbf{1 0 2 . 1 ( 8 5 \% )}$ & $\mathbf{0 . 6 ( 1 \% )}$ & $\mathbf{1 1 9 . 7 ( 1 0 0 \% )}$ \\
\hline Valthermond & 2005 & 7.4 & 6.3 & 106.9 & 0.7 & 121.2 \\
\hline & 2006 & 6.6 & 6.0 & 102.3 & 0.6 & 115.5 \\
\hline & 2007 & 6.3 & 5.8 & 102.8 & 0.6 & 115.5 \\
\hline & Avg. & $\mathbf{6 . 7 ( 6 \% )}$ & $\mathbf{6 . 1 ( 5 \% )}$ & $\mathbf{1 0 4 . 0 ( 8 9 \% )}$ & $\mathbf{0 . 6 ( 1 \% )}$ & $\mathbf{1 1 7 . 4 ( 1 0 0 \% )}$ \\
\hline
\end{tabular}

\section{Energy production}

Figures for ethanol production per hectare are presented in Table 3. Average ethanol yield is 5.7 ton (over $7200 \mathrm{I}$ ) ha ${ }^{-1}$, or $153 \mathrm{GJ} \mathrm{ha}^{-1}$. Both highest and lowest yields are realised in Westmaas. Energy 
input allocated to the production of ethanol is almost similar for both locations. Net energy production in Valthermond (37 GJ ha ${ }^{-1}$ ) exceeds that of Westmaas (32 GJ ha ${ }^{-1}$ ) by $16 \%$. However, the highest net production was found in 2005 on Westmaas.

Table 3. Energy production from sugar beet in Westmaas and Valthermond

\begin{tabular}{|c|c|c|c|c|c|c|c|c|c|}
\hline & Unit & \multicolumn{4}{|c|}{ Westmaas } & \multicolumn{4}{|c|}{ Valthermond } \\
\hline & & 2005 & 2006 & 2007 & Avg. & 2005 & 2006 & 2007 & Avg. \\
\hline Ethanol yield & ton ha ${ }^{-1}$ & 6.7 & 5.9 & 4.4 & 5.7 & 5.9 & 5.7 & 5.7 & 5.8 \\
\hline $\begin{array}{l}\text { Gross energy } \\
\text { production }\end{array}$ & GJ ha $^{-1}$ & 179.5 & 156.9 & 118.5 & 151.6 & 158.7 & 152.0 & 152.6 & 154.4 \\
\hline $\begin{array}{l}\text { Allocated energy } \\
\text { use }\end{array}$ & GJ ha ${ }^{-1}$ & 138.5 & 123.1 & 97.4 & 119.7 & 121.2 & 115.5 & 115.5 & 117.4 \\
\hline $\begin{array}{l}\text { Net energy } \\
\text { production }\end{array}$ & GJ (ha) ${ }^{-1}$ & 41.0 & 33.8 & 21.1 & 31.9 & 37.5 & 36.4 & 37.0 & 36.9 \\
\hline $\begin{array}{l}\text { Energy } \\
\text { efficiency }^{2}\end{array}$ & - & 1,30 & 1,27 & 1,22 & 1,26 & 1,31 & 1,32 & 1,32 & 1,32 \\
\hline
\end{tabular}

${ }^{1}$ Net energy production $=$ gross energy - allocated energy use $;{ }^{2}$ Energy efficiency $=$ gross energy production $/$ allocated energy use

The energy efficiency, defined as gross energy production divided by the allocated energy use, is on average 1.29.As expected, this value is slightly higher in Valthermond (1.32 versus 1.26$)$. This implies that the ethanol energy production by sugar beet is roughly 1.3 times the energy input required, which is comparable to the value of 1.2 reported by Mortimer et al. (2004) but somewhat below the value of 2.0 reported by GTZ/FNR (2006). The difference is partly explained by the fact that the allocation in Mortimer et al. (2004) $(77.5 \%)$ is rather high.

\section{Discussion}

\section{Sugar beet cultivation}

Comparing data on sugar beet cultivation in Westmaas and Valthermond to figures presented by Mortimer et al. (2004) and Dept. of Transport (2007) shows that crop management and cropping conditions in the UK are, with some exceptions, comparable to those described in our study. Major exceptions are found in fertilization, diesel use and application of crop protection agents. Reported phosphate applications are $170 \mathrm{~kg} / \mathrm{ha}$ (Mortimer), as compared to $48 \mathrm{~kg} / \mathrm{ha}$ in Westmaas and $50 \mathrm{~kg} / \mathrm{ha}$ by Dept of Transport. Potassium applications in the UK amount to $226 \mathrm{~kg} / \mathrm{ha}$ (Mortimer) and $120 \mathrm{~kg} / \mathrm{ha}$ (Dept of Transport), as compared to $70-80 \mathrm{~kg} / \mathrm{ha}$ in our study. Manure applications are limited to Valthermond. Applications of crop protection agents in our study (average of $4.2 \mathrm{~kg}$ of active ingredient per ha) are exceeding those reported for the UK $(1.2 \mathrm{~kg} / \mathrm{ha}$ for Mortimer and $0.3 \mathrm{~kg} / \mathrm{ha}$ by Dept of Transport). Diesel use by Mortimer (103 kg/ha) is significantly below levels in our study (164, $125 \mathrm{~kg} / \mathrm{ha}$ ) or reported by Dept of Transport (168 kg/ha). Clearly, higher input use is leading to increased energy use during cultivation. On the whole, energy use during cultivation on Westmaas (11 $\mathrm{GJ} / \mathrm{ha}$ ) and Valthermond (7 GJ/ha) is below the value reported in Mortimer et al. (2004) (13 GJ/ha). No values are specified in Dept of Transport (2007).

A comparison of our input use and yield data with those reported by Märländer et al. (2003) suggests that input use and yields in the Netherlands are comparable to those in Germany.

\section{Energy use and production}

Energy use for the production and distribution of ethanol from sugar beet in the Netherlands, on average $118 \mathrm{GJ} \mathrm{ha}^{-1}$, is above the value reported by Mortimer et al. (2004) of $107 \mathrm{GJ} \mathrm{ha}^{-1}$, the difference being mainly explained by higher beet yields in the Netherlands requiring more energy for transportation, conversion and distribution.

Energy use per ton of ethanol production in The Netherlands, $20-21 \mathrm{GJ} \mathrm{ton}^{-1}$, is almost similar to the value reported by Mortimer et al. (2004), $22 \mathrm{GJ} \mathrm{ton}^{-1}$. This difference is mainly caused by the longer distribution distances in the UK. 
The energy use in the conversion phase is by far the largest of all processes in the chain. Hence, assumptions on conversion efficiency will have a large impact on the results.

As explained by high crop yields in The Netherlands, gross energy production (>150 GJ ha ${ }^{-1}$ ) is high compared to studies. Mortimer et al. (2004), for example report a production of $130 \mathrm{GJ} \mathrm{ha}^{-1}$. Crop yields realised on the Dutch research farms, 70 ton $\mathrm{ha}^{-1}$, exceed those reported by Mortimer et al. (2004) (52 ton ha $\left.{ }^{-1}\right)$. The average net energy production per hectare in the Netherlands of $34 \mathrm{GJ}$ is considerably higher than the 22 GJ in the UK (Mortimer et al., 2004). However, when net energy production is expressed per ton of ethanol the values are almost similar (21 and $20 \mathrm{GJ} / \mathrm{ha}$ on Westmaas and Valthermond compared to $22 \mathrm{GJ} / \mathrm{ha}$, as reported by Mortimer et al. (2004).

On average, energy yield is about 1.3 times the energy used in ethanol production, which is not a particularly good result considering the fact that energy efficiency ratios of first generation bioethanol crops in the northern hemisphere generally vary between 1.5 (maize in the US) and 2.0 (wheat). Energy efficiency for sugarcane in Brazil is around 8 (GTZ/FNR, 2006). The applied energy input for conversion (model 2 from Mortimer et al.; 2004) is rather high. The same source shows that using more efficient energy generating systems (gas turbine combined with CHP systems, models 4a and $4 b)$ can reduce energy requirements over the entire production chain, including energy for cultivation, transportation and distribution, with more than 50\%. Energy efficiency can be improved to 2.8 (Mortimer et al., 2004). This asks for a more detailed analysis of the Dutch energy generation system, as in this study the data for the UK have been applied to the Dutch situation.

In terms of energy efficiency, ethanol production from sugar beet seems promising if energy inputs can be reduced. Technology options for this seem to be available.

\section{Sources of uncertainty}

Most of the parameters that have been used in our calculations have been derived from Mortimer et al. (2004). Ethanol yield from sugar beet has been set at 0.080 ton ethanol per ton of beet (following Dept of Transport, 2007) being 0.002 ton above the value used by Mortimer et al. (2004). Transport distance from the field to the factory is slightly $(20 \mathrm{~km})$ above the value of Mortimer. In contrast to the situation in the UK, transportation distance of ethanol to users in The Netherlands usually is expected to remain below $100 \mathrm{~km}$. We have assumed a value of $100 \mathrm{~km}$.. Doubling the distance from 100 to $200 \mathrm{~km}$ increases energy use with $0.6 \mathrm{GJ} / \mathrm{ha}$ or less than $1 \%$, hence its influence is very small

The impact of the energy allocation ratio over ethanol and by-products is much larger. We have allocated $77.5 \%$ of the energy inputs to ethanol. If a lower value is applied, net energy yield would be increased and the allocation ratio can be considered, after energy use for conversion, the second major factor determining efficiency of bioethanol production from sugar beet. The choice of the allocation ratio is a subjective matter. In this study we have set it to a conservative value, compared to other literature sources.

One of the issues that deserve attention is the amount of energy that is to be allocated to manure production. Allocating an indirect energy value to manure would have increased energy demand for production on Valthermond. For matters of consistency this should have been taken into account, as we also allocated energy to pulp as a by-product. However, this is a complicated subject, depending on the livestock production system in which it is produced. Bos et al (2007) have estimated transport and distribution energy for animal manure. In this study we have not taken this into account, as the amounts applied are small and the net effect on total energy input or net energy production is expected to be limited.

Another issue is the effect of sugar concentration on energy demand during conversion and on ethanol yield. Calculations presented by Mortimer et al.(2003) and by Dept of Transport (2007) do not take sugar concentrations into account. Hence, the results for a crop with a high sugar concentration will not differ from those for a crop with a low concentration. It is expected that crops with high sugar concentrations produce more ethanol per ton of beet. Unclear however is, how much more this will be.

\section{Prospects for improvement}

Net energy production from sugar beet can be increased if crop residues are used in a fermentor, generating additional energy as heat, biogas and/or electricity. Existing combinations of distillation and fermentation installations have shown that this step can lead to considerable improvements both in energy efficiency (lowering external energy input during distillation) as in GHG emission reduction. 
The latter is especially the case if steam required during distillation normally is produced using coal or heavy fossil fuels as normally is the case in the US. Of course, positive effects of such a step have to be compared to potentially negative effects, such as additional transportation of crop residues to the factory and transportation of digestate back to the fields. Experiments applying digestate as fertiliser suggest that nutrient efficiency of the digestate is equal or superior to that of manure.

Further improvements can be realised if energy use during the processing can be reduced by means of technical improvement. This is the most energy consuming phase in the sugar beet chain. Positioning production and conversion units closer to each other and to end users will also have a positive effect on energy efficiency and GHG emissions, but transport is only a small fraction of the energy inputs. Thus, in order to arrive at maximum GHG emission reduction, selection of the most efficient conversion technique should be given priority. If necessary it could lead to overruling of optimal feedstock transportation decisions.

\section{Conclusion}

Prospects for ethanol production from sugar beet in The Netherlands seem promising. Crop yields are above the European average, as is ethanol production per hectare. Under prevailing conditions, production of bioethanol from sugar beet has an energy efficiency of 1.3. The conversion process consumes $85-90 \%$ of all energy inputs, crop cultivation takes $6-9 \%$ and the remainder is for transport and distribution. If energy inputs in processing are reduced, which seems possible by more efficient processes and using crop residues, the energy efficiency can increase considerably. The energy allocation ratio to main and by-product is a subjective matter and its value influences the net energy production.

\section{References}

Bos, J., J. de Haan en W. Sukkel, 2007. Energieverbruik, broeikasgasemissies en

koolstofopslag. De biologische en de gangbare landbouw vergeleken. Rapport 140, Plant Research International, Wageningen.

Department for Transport, 2007. Carbon and Sustainability Reporting Within the Renewable

Transport Fuel Obligation. Requirements and Guidance. Draft Government Recommendation to RTFO Administrator. Report, London.

Elsayed, M.A., R. Matthews and N.D. Mortimer, 2003. Carbon and energy balances for a

range of biofuels options. Project number B/B6/00784/REP. URN 03/836. Report, Sheffield Hallam University, Sheffield.

GTZ/FNR, 2006. Biofuels for transportation. Global potential and implications for sustainable

agriculture and energy in the 21st century. Report, German Agency for Technical Cooperation (GTZ), Eschborn, and German Agency of Renewable Resources (FNR).

Märländer, B., C. Hoffman, H.-J. Koch, E. Ladewig, R. Merkes, J. Petersen and N.

Stockfisch, 2003. Environmental situation and yield performance of the sugar beet crop in Germany: heading for sustainable development. J. Agron. \& Crop Science 189, 201-226.

Mortimer, N.D., M.A. Elsayed, and R. E. Horne, 2004. Energy and greenhouse gas emissions

for bioethanol production from wheat grain and sugar beet. Final report for Britisch Sugar plc, pp. 180. Resources Research Unit School of Environment and Development, Sheffield Hallam University, Sheffield. 


\section{Annex Parameter values}

Table A.1 Parameter values used in calculations compared to Mortimer et al. (2004).

\begin{tabular}{|l|c|c|c|c|}
\hline & Unit & Westmaas & Valthermond & $\begin{array}{l}\text { Mortimer et al. } \\
(\mathbf{2 0 0 4 )}\end{array}$ \\
\hline $\begin{array}{l}\text { Transportation field to factory and } \\
\text { back }\end{array}$ & $\mathrm{Km}$ & 100 & 100 & 80 \\
\hline Energy use for transportation & $\mathrm{MJ} \mathrm{ton}^{-1} \mathrm{~km}^{-1}$ & 1,1053 & 1,1053 & 1,1053 \\
\hline Conversion beet to ethanol & ton ton $^{-1}$ beet & 0,080 & 0,080 & 0,078 \\
\hline Energy use for conversion & $\mathrm{MJ} \mathrm{ton}^{-1}$ ethanol & 17.992 & 17.992 & 17.992 \\
\hline $\begin{array}{l}\text { Transportation factory to user (and } \\
\text { back) }\end{array}$ & $\mathrm{Km}^{\text {Energy contents of ethanol }}$ & 100 & 100 & 450 \\
\hline Energy contents N fertiliser & $\mathrm{MJ} \mathrm{kg}^{-1}$ & 26,8 & 26,8 & $26,7^{2}$ \\
\hline Energy contents P fertiliser & $\mathrm{MJ} \mathrm{(kg} \mathrm{P2O5)}^{-1}$ & 41,8 & 41,8 & 40,6 \\
\hline Energy contents K fertilisert & $\mathrm{MJ} \mathrm{(kg} \mathrm{K2O)}^{-1}$ & 5,2 & 5,2 & 15,8 \\
\hline Energy contents herbicides & $\mathrm{MJ} \mathrm{kg}^{-1}$ & 269 & 5,8 & 27,3 \\
\hline Energy contents fungicides & $\mathrm{MJ} \mathrm{kg}^{-1}$ & 176 & 176 & 274 \\
\hline Energy contents insecticides & $\mathrm{MJ} \mathrm{kg}^{-1}$ & 583 & - & 274 \\
\hline Energy content manure & $\mathrm{MJ} \mathrm{t}^{-1}$ & - & Not available & Not available \\
\hline
\end{tabular}

${ }^{1}$ Energy use allocated to main (79.2\%) and by products (10.8\%) based on ratio of prevailing market values of main and by-products in the UK during the time the calculations were done; ${ }^{2}$ Including direct energy only (defined as Lower Heating Value or LHV). 